Bradley W. Root

\title{
First Century Galilee
}

\section{A Fresh Examination of the Sources}

[Galiläa im ersten Jahrhundert. Eine neue Untersuchung der Quellen.]

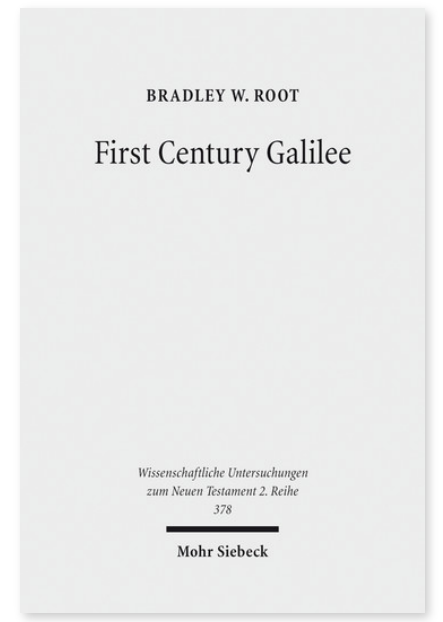

2014. XVII, 228 Seiten. WUNT II 378

ISBN 978-3-16-153541-3

DOI 10.1628/978-3-16-153541-3

eBook PDF $89,00 €$

ISBN 978-3-16-153489-8

fadengeheftete Broschur $89,00 €$
Veröffentlicht auf Englisch.

Bradley W. Root bietet eine gründliche neue Untersuchung der relevanten Literatur und archäologischen Belege für das Galiläa des ersten Jahrhunderts. Root stellt die These auf, dass die bisherige Forschung über Galiläa es versäumt hat, zwischen den verschiedenen Informationsquellen für die Geschichte der Region zu unterscheiden. Deshalb wendet er eine strenge Methode der historischen Untersuchung an, indem er jede relevante literarische Quelle und die archäologischen Belege einzeln auswertet bevor er alle Indizien gemeinsam deutet. Root schließt mit einer historischen Rekonstruktion des Galiläas des ersten Jahrhunderts und zeigt, dass die Region bis zum Jüdischen Krieg im Jahr 66 n.Chr. politisch stabil war. Außerdem erläutert er, dass die Kultur in Galiläa maßgeblich von der jüdischen Kultur beeinflusst wurde und dass Galiläa bedeutend weniger sozial-ökonomische Probleme als Judäa hatte. Zudem vertritt er die These, dass die jüdischen Gemeinden entlang des Sees Genezareth ihre eigene regionale Kultur entwickelten.

Bradley W. Root Born 1980; 2002 BA in History; 2009 PhD in Ancient Jewish History; 2011-14 Visiting Assistant Professor of History at St. Mary's University (San Antonio, Texas); currently Assistant Professor of Ancient History at St. Mary's University.

\section{Jetzt bestellen:}

https://mohrsiebeck.com/buch/first-century-galilee-9783161535413?no_cache=1

order@mohrsiebeck.com

Telefon: +49 (0)7071-923-17

Telefax: $+49(0) 7071-51104$ 